\section{NOTES OF A CASE IN WHICH LARYNGITIS FOLLOWED THE ADMINISTRATION OF CALOMEL.}

Bx JOHN LOCKING, M.D., PHYSICIAN TO THE ISLINGTON DISPEN SARY.

THE following notes may be considered of interest as illustrating the risk which may sometimes attend the administration of calomel.

J. S_- aged twenty-six, of florid complexion and stout build, had always enjoyed excellent health up to the 17 th of May, 1866. The son of a small farmer, and residing with his parents, he had been hoeing corn on the day preceding the above date, when, feeling fatigued and over-heated, he sat down under a hedge to rest. It was one of those bright sunny days in spring, a treacherous sharp east wind prevailing. He got a chill, which was succeeded on the following day by shivering and pain in the abdomen.

I was sent for on the 18th, and found him in bed lying on his back, with the thighs drawn upwards, and flexed on the abdomen. His pulse was small, hard, and rapid; urine scanty and high-coloured; countenance anxious. In short, he was suffering from acute peritonitis. A large mustard poultice was applied at once, followed by hot linseed poultices. I prescribed small doses of opium to be taken frequently.

On the following day he was in much the same condition. I therefore ordered flannels, steeped in turpentine, to be applied to the abdomen as hot and as often as they could be borne, and the hot linseed poultices repeated in the intervals. Soon after this the activity of the symptoms began to subside, and on the 23rd he appeared free from all trace of the disease. But his bowels had not been relieved for four days, and, as he began to be uneasy, 1 thought it well to give a purgative. As he had had no mercury, and dreading to exhibit anything which might light up slumbering embers (if such remained) of the disease from which he appeared to be recovering so nicely, and as mercury is held to be in one of its actions anti-inflammatory, it being used, moreover, and recommended in the treatment of peritonitis, I thought the safest purgative I could give my patient would be a combination of that drug. I accordingly prescribed one grain of calomel, along with five grains of jalap, to be taken every three hours until the bowels were moved. Immediately after he had taken the sixth powder he had a copious evacuation, without griping or other unpleasant symptom. Other loose motions followed, and he appeared much better. But mark the sequel : before six hours had elapsed after taking the last powder, and within twenty.four hours of having taken the first, salivation set in, and he com. plained of great fulness in the sublingual region. He soon began to experience a little difficulty in breathing, and during the night of the 24 th he was very restless.

Before my visit on the following morning he had filled the chamber vessel literally full of mucus and saliva. On inspection, I found the tongue, tonsils, and uvula much swollen, the latter being of a bright red colour; but there were no aphthæ nor any ulceration. Dysphagia and stridulous breathing now became marked features, the latter continually growing louder. A blister was applied over the windpipe, and hot poultices round the neck. On the evening of the 25 th he could swallow nothing. On the morning of the 26 th he was much worse: countenance turgid, lips blue, and the dyspncea painful to witness. I informed his friends the case was hopeless unless tracheotomy was performed, but to this they would not consent. In the evening $I$ was summoned to the patient in a hurry. Being knocked up with hard work, and feeling very unwell, I sent to a neighbouring practitioner, who very kindly went off at once to see him. In a note which this gentleman wrote as soon as he had seen the patient he says : "The man is very ill, and I have recommended leeches and ice, and I should think two grains of calomel every hour, to induce rapid mercurialisation, would be proper for him. The blister has risen well." Of course he was not aware of the train of symptoms, including mercurialisation, which had preceded the condition in which he found the patient; he therefore prescribed for laryngitis in the orthodox manner. The leeches I was told were duly applied, but as the poor fellow was unable to swallow he could not take the calomel. He sank within eight hours of my neighbour seeing him.
The case gave me great anxiety at the time, and it left a powerful impression on my mind. Death was due to laryngitis. The inflammation in the windpipe was not a metastasis, for the peritonitis had subsided several days. Besides which, before the larynx became affected there was profuse salivation, accompanied with swelling and pain of the tongue, and swell. ing and redness of the tonsils, uvula, and parts adjacent. The inflammation appeared first in these organs, and then spread by continuity to the larynx. But the salivation, tonsillitis, \&c., were, it is fair to assume, owing to absorption into the system of some of the calomel, which was taken as a purge. Six grains were taken in all, combined with thirty grains of jalap; and notwithstanding the fact that brisk purgation ensued, yet most violent symptoms of the physiological action of mercury showed themselves within a few hours.

This history conveys two lessons-1st. That purgation is no certain safeguard against absorption. 2nd. That the exhibition of a drug endowed with various therapeutical and physiological actions may not be without danger.

Consaught-square, Hyde-park, Oet. 1868.

ON

SCARIFICATION OF THE CERVIX UTERI IN INFLAMMATORY AFFECTIONS OF THE WOMB.

By R. H. MEADE, F.R.C.S., CONSULING SURGEON TO THE BRADFORD INFIRMARY.

THE management of some of the diseases of the uterus often occasions much trouble and considerable disappointment to the surgeon engaged in general practice. I shall therefore make no apology for offering a few observations on the mode of treatment which $I$ have found most successful in a class of cases which is perhaps more frequently met with than any other among these affections.

The forms of uterine disease to which I particularly wish to direct attention are those inflammatory states of the organ in which congestion, inflammation, and ulceration of the cervix play so prominent a part. The causes and varieties of these affections are very numerous. We often find the cervix swollen and red; sometimes it is partly denuded of epithelium, and assumes a granular appearance, having a velvety feel to the touch ; and sometimes it is decidedly ulcerated. With regard to the causes, anything that produces determination of blood to the uterus, or excites inflammatory irritation of the organ, may bring on inflammation or ulceration of the cervix.

These complaints are, as might be expected, much more common among married than single women, and in many instances follow miscarriage, or labour at the full period of gestation. They often accompany menorrhagia and dysmenorrhca. In most of these cases, as Dr. West has pointed out, the visible state of disease in the cervix is only an indication of a more deeply seated, but hidden inflammatory condition of the body of the womb; the treatment therefore should be such as will relieve the whole organ.

These complaints are sometimes connected with, and apparently produced by, general constitutional disorder, and require appropriate general treatment. Still many of them are in a great measure local, owing to the physiological peculiarities of the uterine organs. During the periodical determination of blood natural to the menstrual period the uterus is exposed to increased danger from accidental causes, as exposure to cold, violent exertion, \&c.; and marriage, pregnancy, abortion, and delivery are still more fruitful causes of local mischief. Our treatment, therefore, must be chiefly directed to the uterus itself.

Where true ulceration exists, great benefit will doubtless accrue from the use of caustics, the nitrate of silver appearing to me to be the one most generally applicable; but when the neck of the womb is enlarged and abnormally vascular, show. ing that the walls and lining membrane of the body of the organ are similarly affected, what will relieve the patient so speedily or effectually as the local abstraction of blood?-and the point to which I wish to direct attention is as to the best mode of effecting that object.

Local bleeding has been prominently brought forward, as 